\title{
Railway Track Finding System with RFID Application
}

\author{
Anand Kr. Gupta \\ Department of ECE \\ CSJM university \\ Kanpur-208024,UP,India
}

\author{
Sushant Katiyar \\ Department of ECE \\ CSJM university \\ Kanpur-208024,UP,India
}

\author{
Nitin Kumar \\ Department of ECE \\ CSJM university \\ Kanpur-208024,UP,India
}

\begin{abstract}
The Indian Railways is world's fourth largest railway network in the world after USA, Russia and China. There is a severe problem of collisions of trains. So Indian railway is working in this aspect to promote the motto of "SAFE JOURNEY". A RFID based railway track finding system for railway has been proposed in this paper. In this system the RFID tags and reader are used which are attached in the tracks and engine consecutively. So Train engine automatically get the data of path by receiving it from RFID tag and detect it. If path is correct then train continue to run on track and if it is wrong then a signal is generated and sent to the control station and after this engine automatically stop in a minimum time and the display of LCD show the "WRONG PATH". So the collision and accident of train can be avoided. With the help of this system the train engine would be programmed to move according to the requirement. The another feature of this system is automatic track changer by which the track jointer would move automatically according to availability of trains.
\end{abstract}

\section{Keywords}

RFID, Railway Track Finder, Train Collision Avoidance, Track Atomization.

\section{INTRODUCTION}

The train accident generally happens because of human error and failure of the machines. The Indian railway losses huge amount of money due to cancellation of trains during winter every year. Also it is quite difficult to run the trains properly during winter season. The main reason behind this problem is fog. The Indian Railways has worked on many technologies to overcome these hindrances .The author has worked on a prototype that leads to innovative approach to tackle with the problem faced by railways. Although many inventions have taken place in India to curb the problem of accidents and traffic problem in train[1].The $\mathrm{ACD}$ (Anti collision device) is developed by konkan railways which uses the GPS technology for tracking the position updates of the train. It is quite helpful and in practice in southern region of India [2]. But it is inadequate for detection of rail tracks separated by a distance of $10-15$ feet because of limitations of accuracy of gps in our country. The ACD makes use of embedded controls and a GPS system thereby preventing collision between trains. However, this system does not take into account factors based on the environment. As a result, accidents due to other factors such as collapsing of bridges or derailment cannot be overcome. The author has developed the system which uses the RFID technology to locate the train. This prototype also leads to atomization of railways so far. A new system like the black box in aero planes named data logger is also installed in the system. Data logging is the measuring and recording of physical or electrical parameters over a period of time. Data loggers are used in a variety of applications such as in-vehicle data logging, environmental monitoring, structural health monitoring, and machine condition monitoring [3]. If in extreme case the accident happened the exact information about these parameters can be taken out so that the fault can be find. The author has also made the unique feature of automatic track changer which can rotate according to the availability of trains on tracks. Here track changer means the small piece of track which is used to join the tracks The figure of the prototype give better perception of it. The goal of this work is to design and implement a cost effective system with the help of RFID and microcontrollers. This system is overall wireless which uses the wireless transmission technology. This system uses the application of RFID which is cost effective and have unique feature of identity[4]. In this prototype the train is controlled with the help of microcontrollers. The train work according to the instruction given by the microcontroller. The microcontrollers are programmed according to the path of train. Once the train starts running according to the programmed it follow the path which is predefined by the controller of the train. If the train chooses another path because of human error or track misplacing the train will automatically stop in the limited time so that accidents caused by this reason can be avoided. 


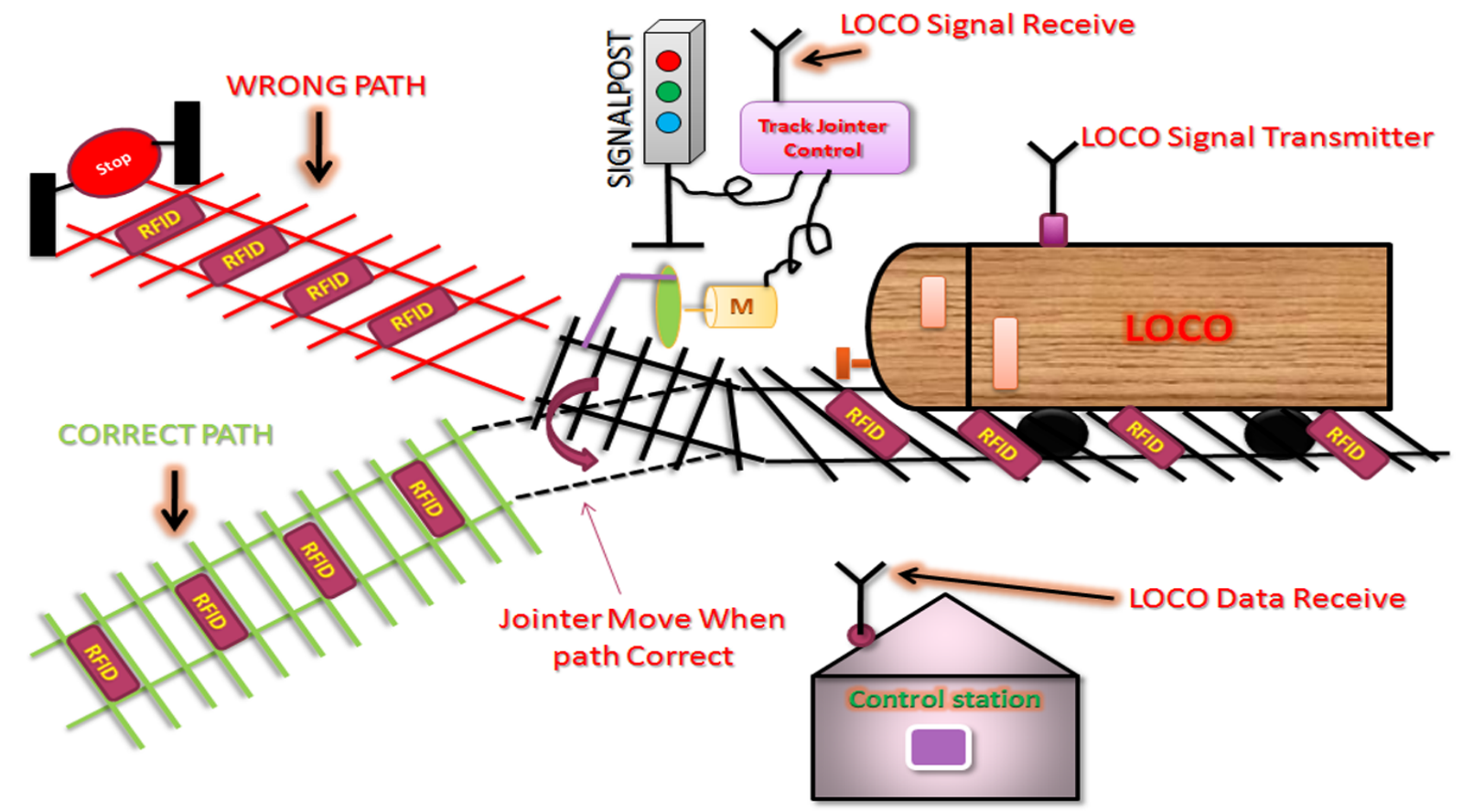

Fig 1: Schematic representation of the RTFS (Railway Track Finding System)

\section{OVERVIEW OF PROPOSED SYSTEM}

The railway is manipulating new systems to enhance its working .Active and Passive RFID has done a great advancement in terms of applications. RFID has been used in innumerable applications so far. Active RFID needs continuous power whereas Passive RFID is powered by the reader when RF energy is transferred from it to the tag[5]. So here the author has used them for the implantation of new technology where RFID is implemented on the railway engine and the RFID tags are attached in the tracks between some specific distances. The main coil is in RFID reader with a power supply and RFID tag also has a coil and a small chip mainly RAM which contain the 12 bit unique code. RFID is one of the technology which is used for Automatic Identification like voice recognitions and smart card. It uses the principle of inductive coupling and electromagnetism and works without the physical contact between reader and tag. RFID works on the different frequency levels for different purposes[6].

The Indian Railways is working on the utilization of RFID for the betterment of transportation and signal handling. The application of RFID is used by many industries for tracking their products. Here the author is using passive RFID tag. The passive tag is a RFID tag that does not contain battery, the power is supplied by the reader when it reaches in proximity with the tag[7]. When waves from the reader fall on a passive RFID tag, the coiled antenna within the tag starts to induce the magnetic field. The tag draws power from it, and forwards it to the circuits in the tag. The tag then sends the information encoded in the tag's memory.

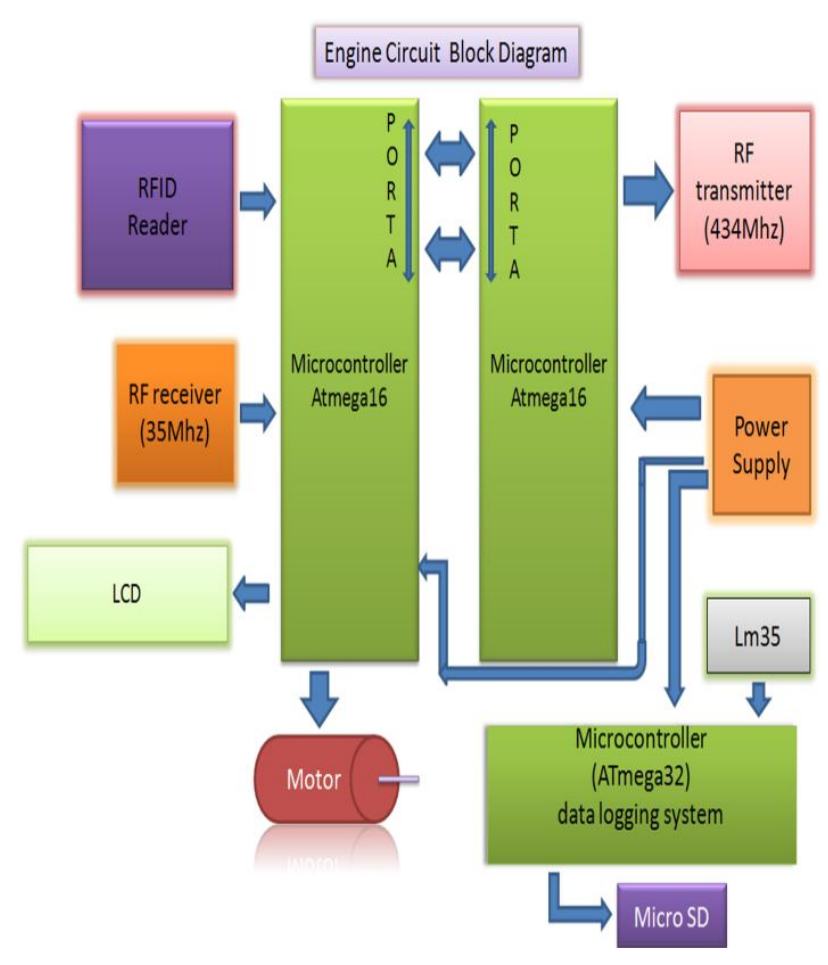

Fig 2: Block Diagram Representation of Subsystem in Train 


\subsection{The passive RFID tag consists of following parts-}

- The chip is made up of silicon that contains data

- The chip is attached to an antenna by which the code is transmitted

- The chip and coil is mounted on the plastic cover

The prototype made by author consists of a small railway engine (loco) and a small wagon. The engine size is kept according to the size of circuits which are installed in the engine. The wagon is so made that the power supply (batteries) can be put into it .The power supply is transferred to the circuits in the engine with the help of wires. The model of the prototype is shown in Fig 1.

\subsection{The loco consists of following circuits 1. Control Panel}

2. Data logger circuit

3. RFID reader circuit

4. Track changer

5. Track jointer control

\subsection{Subsystem of Control panel}

This Control panel is made in engine and for real application in the engine author has developed another control panel with the use of LAB VIEW .The control panel in the engine consist of LCD, supply switches, data pins. LCD is used for displaying the 12 bit unique code of RFID tag. Data input pins are used to programme the microcontrollers in the engine. A 9 pin female connector is used as data input here. A buzzer is also attached in control panel it create sound when the RFID reader installed below the engine reaches near to the RFID tag in the tracks. There is specific proximity for the data to transfer from RFID tag to RFID reader. The RFID tag when come in the range of the reader it sends the data of unique code of each RFID. The microcontrollers are mainly used to program the working of a train. Microcontrollers are working as the main domain of the project which are helpful in programming of data logger, RFID receiver, RFID code transmitter. In data logger SD card is used to store the real time data of the train. The tracks are made with the help of wooden material and hard plastic sheets .The difference between the tracks is kept according to the width of the engine so that it can run easily on it. The tracks are made in the shape of alphabet "Y". So in demonstration the train can go in two paths according to availability and nonavailability of trains on tracks. The working of the prototype is fully based on the RFID tag code receiving and transmission. So if It receives the incorrect TID then the motors of loco stop after a limit of minimum time and if it receives the correct TID which is stored it the programming of microcontroller then the loco continue to run.

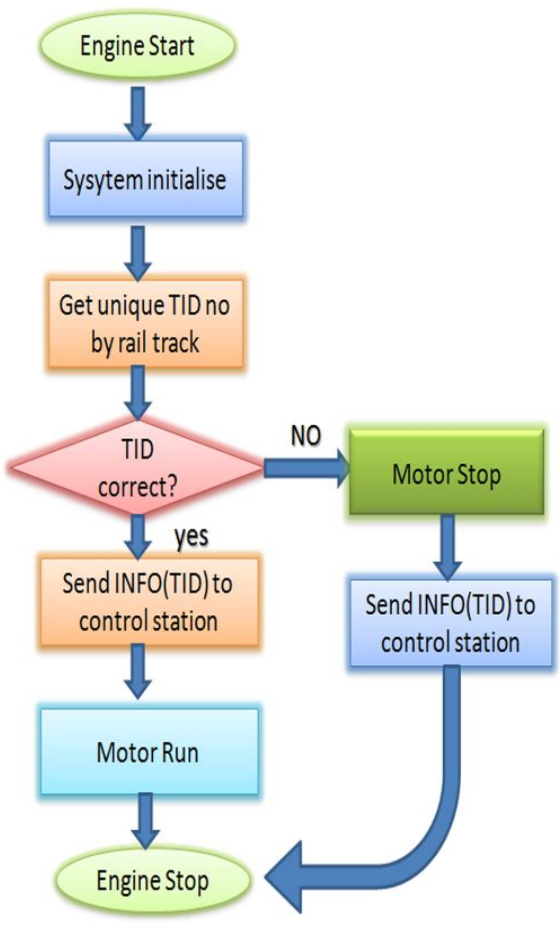

Fig 3: Flow Chart of Loco Control

\section{USED SOFTWARE FOR CONTROL} PANEL

For control panel display used LAB VIEW to make the control panel friendly to the controller. More features can be added to this control panel and make them controllable. At the prototype level lab view has helped a lot to evaluate this graphic user interface. This is simply control panel of the train which show the running parameters of the train. The controller has to enter only source and destination station in it. The train is start with the help of engine start/stop switch and it show the real time speed and temperature of the engine. The horn switch is also there which is manually controlled. This control panel in the wider context can be replaced by the touch screens. The fig is show in $4 \&$ 5respectively. The LAB VIEW is interfaced with arduino kit to provide the instruction transmission from this screen to the circuits [8].Arduino is an opensource electronics prototyping platform based on flexible, easy-to-use hardware and software. In LAB View graphical coding also possible so that it is most user friendly. Microcontroller signal can easily reach computer through LAB VIEW [9]. One more thing we can easily check, getting signal type and amplitude. Analysis of received signal very easy. 


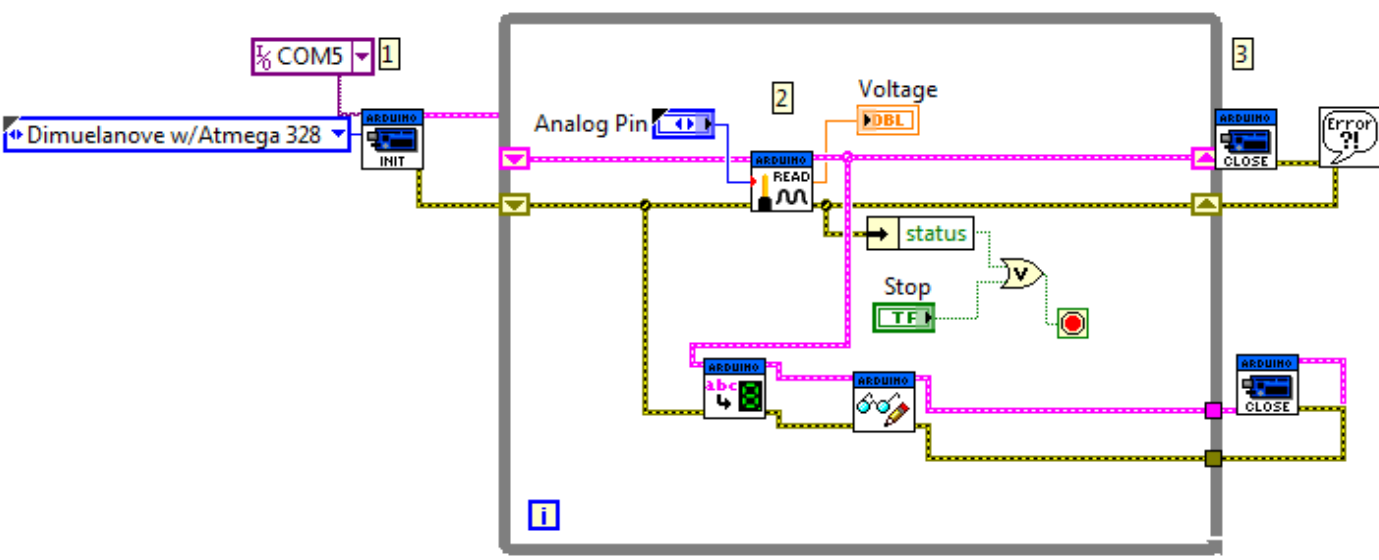

Fig 4: Snapshot of A LAB VIEW Program

\section{SUBSYSTEM IN CONTROL STATION}

A Control station is also made which can show the location of train with the help of blinking led's. A microcontroller is also used in this section so that the live position of the train can be traced. This is working on the basis of wireless transmission of signal from the engine with the help of receiver -transmitter pair. The transmitter is attached in the engine while receiver is attached with the control station. A separate circuit is designed for the control station which is controlled with microcontroller. The Flow chart of control station working show in fig.6. If any train goes to the wrong path then engine send a signal and control station receive this signal quickly and turn on a buzzer which show that something is wrong with the engine. Information which show in control panel also send to control station so that control station LCD show the same information at a time. This is helpful for cross check of track data. If driver does not take any decision then control station engineer also send a stop signal for engine. A control station is a wireless signal Receiver when train is near to the station then station receiver the broadcast signal which is transmitted by the engine and then control station show the all information about coming train.

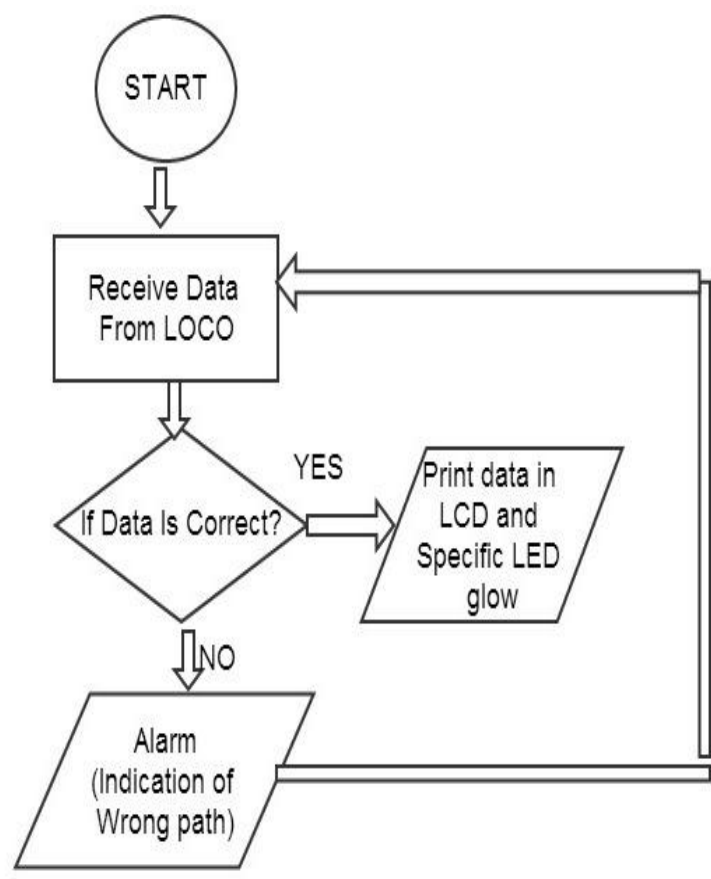

Fig 6: Flow chart of control station working 


\section{Automatic railway Track Identifier Engine Control}
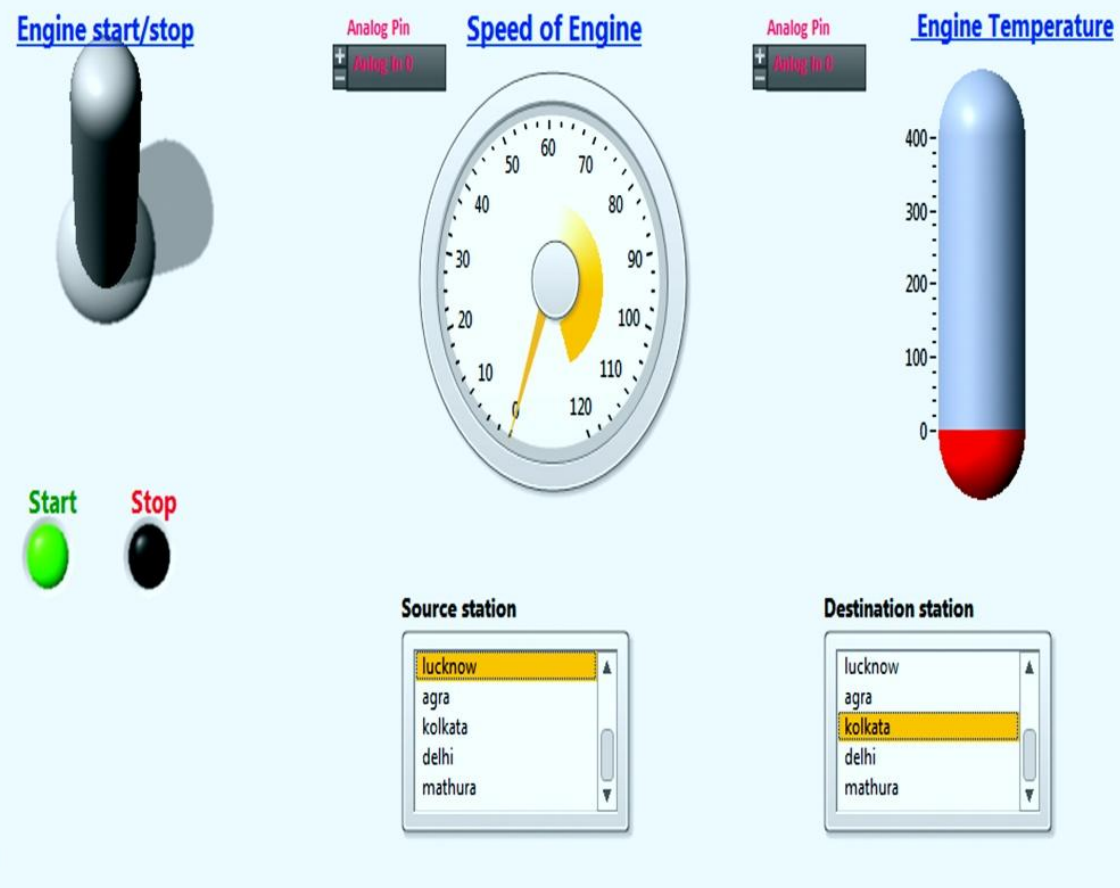

HORN

Source station

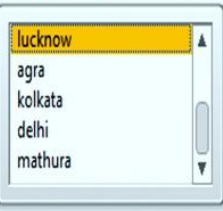

Destination station

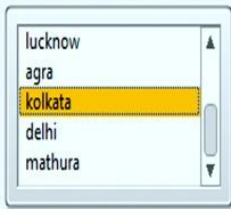

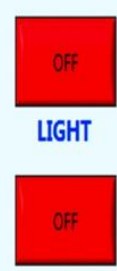

Signal Transmit

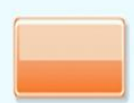

Fig 5: Representation of control panel designed with the help of LAB VIEW

\section{TRACK CHANGER CIRCUIT}

The Track changer is also made which is used to join the tracks .It is joined with the motor by which it can rotate .In the prototype the jointer is installed between the tracks and is able to rotate on its axis. The weight sensors are used on the tracks when a train reaches on track the weight sensors send a signal to the motors of rotatory jointer and the jointer moves to the direction opposite to coming train and give the way to the coming train so that it can pass over it . A signal post is also made to demonstrate the working of track jointer. It has installed with the LED of 3 colours ie.Red, blue and green. They blink when the weight sensor send signal to motor and the track take its position. The colours provide the visual signal that now the track is ready to pass. The Track changer circuit show in fig $7 \& 8$ respectively.

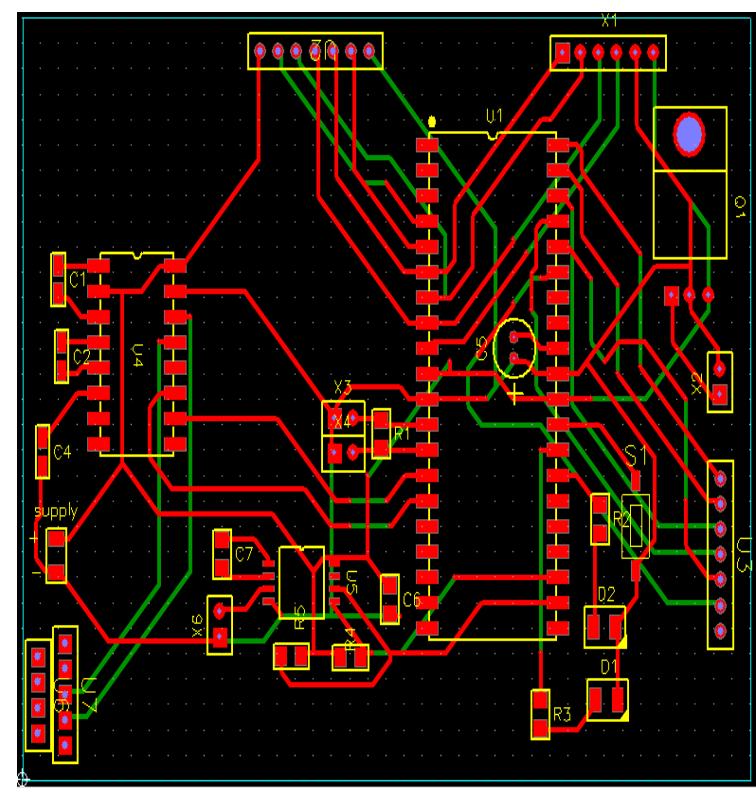

Fig 7: Track Changer PCB 


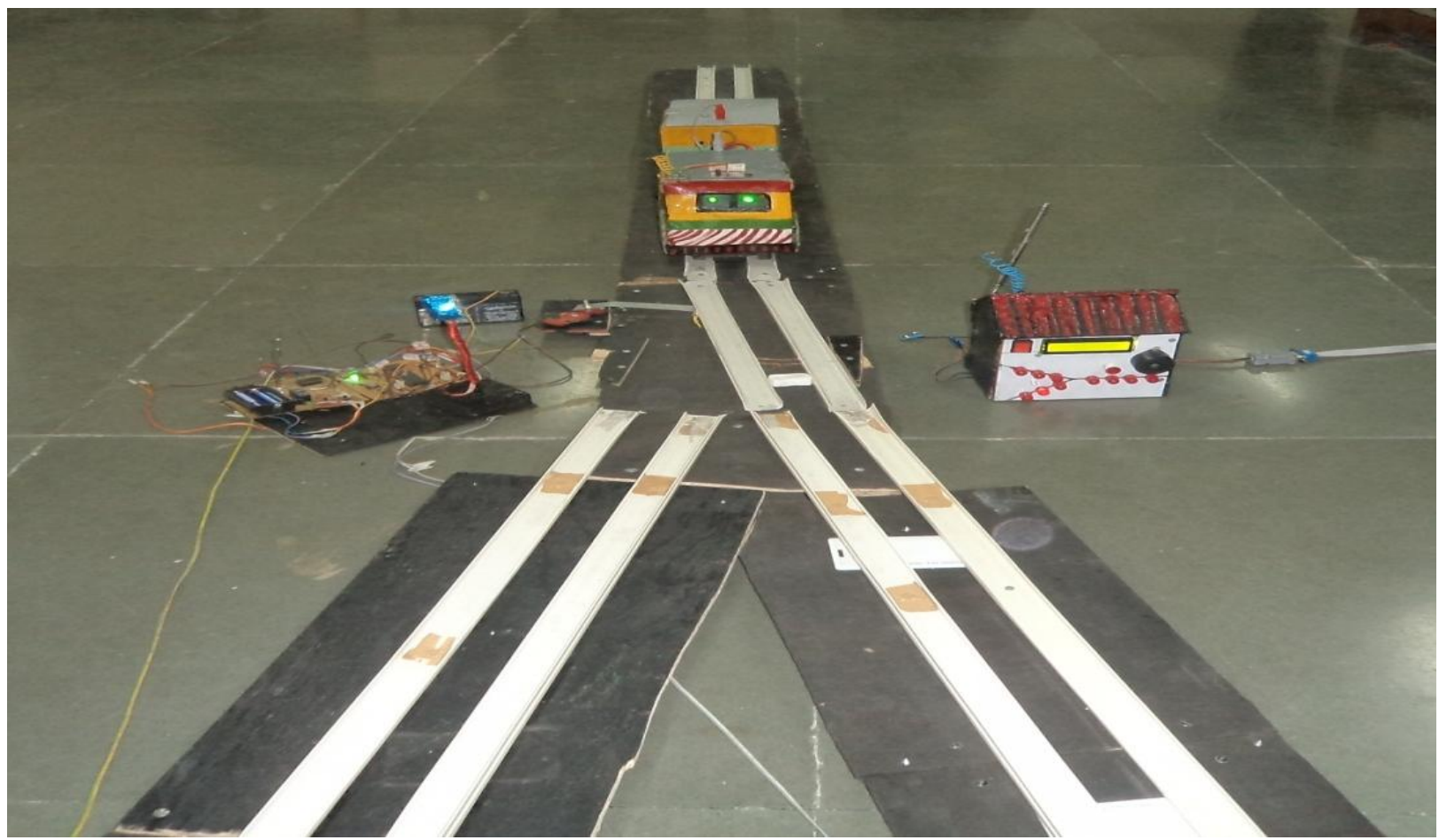

Fig 8: Real picture of the prototype

\section{RESULTS AND ANALYSIS}

The prototype is tested for the work which is given to it and described in the paper. This is a modern approach towards atomization of railways. The every component has worked successfully .This work presented by author is more effective when use at the practical level. Here prototype has performed well with the idea for which it is made. The control station in the prototype is a nearest station which keeps the whole information about the train. The ATIS(Automatic Train Identification System)[10] is developed by engineers of china is quite successful in tracking of good train..But RTIS has some of unique features over it and these are as follows

\begin{tabular}{|c|c|c|}
\hline & RTIS SYSTEM & ATIS TECHNOLGY \\
\hline 1 & $\begin{array}{l}\text { It can track the train } \\
\text { anywhere }\end{array}$ & $\begin{array}{l}\text { This technology can trace } \\
\text { the goods train when it is } \\
\text { near the station }\end{array}$ \\
\hline 2 & $\begin{array}{l}\text { The RFID cards are } \\
\text { used in between the } \\
\text { railway tracks at a } \\
\text { limited distance .here } \\
\text { RFID is used to locate } \\
\text { the position of train } \\
\text { anytime. }\end{array}$ & $\begin{array}{l}\text { In this technology the } \\
\text { RFID tags are pasted with } \\
\text { the goods which are in the } \\
\text { train so they can be } \\
\text { located easily. }\end{array}$ \\
\hline 3 & $\begin{array}{l}\text { The data logger is } \\
\text { used } \\
\text { by which the required } \\
\text { information about the } \\
\text { train could be taken. }\end{array}$ & $\begin{array}{l}\text { It Takes the state } \\
\text { information of train with } \\
\text { the help of database. This } \\
\text { does not trace the } \\
\text { different variables of train } \\
\text { except train number. }\end{array}$ \\
\hline 5 & $\begin{array}{l}\text { Here the system is } \\
\text { based } \\
\text { on the RFID tags and } \\
\text { reader and the }\end{array}$ & $\begin{array}{l}\text { Here RFID and ATIS are } \\
\text { working to make a } \\
\text { complete system } \\
\text { ie.database of ATIS }\end{array}$ \\
\hline
\end{tabular}

\begin{tabular}{|c|c|c|}
\hline & $\begin{array}{l}\text { transmission and } \\
\text { reception of data. }\end{array}$ & \\
\hline 6 & $\begin{array}{l}\text { Developed for } \\
\text { reducing } \\
\text { the train accidents and } \\
\text { atomization }\end{array}$ & $\begin{array}{l}\text { Developed for tracking } \\
\text { of good from one place } \\
\text { to another. }\end{array}$ \\
\hline
\end{tabular}

\section{CONCLUSION}

The prototype made by author is the key idea for the practical application. It will modify the working of railways if implemented .The cases of accidents can be reduced extensively. This approach is so much cost effective and installation of RFID tag is so easy. After installation this approach provides many features over the technology which is running presently in railways. This prototype also leads to exact tracking of the train i.e. its location can be traced clearly at every point. The future aspect of this system is so important. It would reach to full automation of railways. The distance between each train can be maintain according to the requirement with the application of this sytem.The High speed trains can also run with the help of this technology of using RFID.

\section{REFERENCES}

[1] Siror, J.K. ; Compute. Sci. \& Eng. Dept., Shanghai JiaoTongUniv.,Shanghai,China; ShengHuanye ; Wang Dong; Wu Jie, Use of Rfid Based Real Time Location Tracking System to Curb Diversion of Transit Goods in East Africa.

[2] Bhatt, Ajaykumar A, 'An Anti-Collision Device Network - A train Collision Prevention System (TCPS)'. 
[3] Suzdalenko, A., "Guidelines for autonomous data logger design," Industrial Electronics (ISIE), 2011 IEEE International Symposium on, vol., no., pp.1426,1429, 27-30June2011

[4] Information about the working of RFID :http://www.eecs.harvard.edu/cs199r/readings/ rfidarticle.pdf

[5] Arunabh Chattopadhyay and Ayyangar R. Harish, "Analysis of low range Indoor Location Tracking techniques using Passive UHF RFID tags," Radio and Wireless Symposium, IEEE 22-24, January, 2008, page(s):351 - 354 .

[6] provide information about different frequencies used by RFID:

http://www.ieee.org/about/technologies/emerging/rfid. pdf

[7] passive RFID is used in project and quite good account of knowledge about it is provided: http://www.atlasrfid.com/Technology/ActivevsPassive .aspx
[8] provide information about the human interfacing of the screen with the help of arduino: http://www.arduino.cc/

[9] labview used as tool to make the user interface quite worthy and easy and this reference has contributed quite to enhance knowledge about

LABVIEW: http://www.ni.com/labview/

[10] Transportation Management; XUE Xiaoping,College of Electronics and Information Engineering,Tongji University Shanghai; ChinaMEI Su-ping,College of Electronics andInformation Engineering,Tongji UniversitShanghai, China;CHEN Chen-hui Shanghai ShentieInformation EngineeringCo., Ltd. Shanghai, China;ZHANG Hai-juan Jiangsu Normal University ofTechnology;Changzhou.,ChinaThe 1st International Conference on Information Science and Engineering RFID and ATIS Information System based RailwayContainer (ICISE2009) 